\title{
GÊNERO E AGRICULTURA FAMILIAR: A EXPERIÊNCIA DOARMAZÉM DA AGRICULTURA FAMILIAR E ECONOMIA SOLIDÁRIA NO MUNICÍPIO DE SERRINHA-BAHIA.
}

Vanderleia Alves de Oliveira ${ }^{1}$; Acácia Batista Dias ${ }^{2}$; Ildes Ferreira de Oliveira ${ }^{3}$

1. Bolsista PIBIC-Af/CNPq, Graduanda em Psicologia, Universidade Estadual de Feira de Santana, e-mail: oliveiraavanderleia@hotmail.com

2. Orientadora, Departamento de Ciências Humanas e Filosofia, Universidade Estadual de Feira de Santana, e-mail: acaciabatista02@gmail.com

3. Coordenador do Projeto Ser Tão Forte: Desenvolvimento Territorial Sustentável, e-mail: ildesferreira@gmail.com

PALAVRAS-CHAVE: Mulher Rural; Gênero; Empreendimento Solidário.

\section{INTRODUÇÃO}

O presente trabalho é resultado de uma pesquisa realizada no município de Serrinha-BA, o qual apresenta de acordo com o IBGE (2010) uma população de 76.762 e densidade demográfica de 122,97 hab/ $\mathrm{km}^{2}$ e faz parte da Território do Sisal.

O Armazém surge como uma proposta de inovação no âmbito da comercialização, a partir da constatação, pelos agricultores e agricultoras, da necessidade de uma central para revender seus produtos. A literatura destaca que as organizações surgem a partir de interações sociais, por meio da articulação e da associação de pessoas que se reconheçam por possuir objetivos ou necessidades comuns, procurando o seu fortalecimento pela organização e instrumentalização (REISDORFER, 2014).

Pesquisar o Armazém da Agricultura Familiar foi uma escolha impulsionada pelo desejo de conhecer melhor um projeto piloto que ganha destaque, devido a sua participação no desenvolvimento das/dos agricultores da referida região, e promove a visibilidade, em especial, das trabalhadoras rurais.

\section{MATERIAL E MÉTODOS}

Para a produção desse trabalho realizou-se leituras, fichamentos, busca de informações em sítios, além da realização de quatro entrevistas semiestruturadas com mulheres participantes de entidades distintas e ligadas ao Armazém: a presidente da União Nacional das Cooperativas da Agricultura Familiar e Econômica Solidária (Unicafes), a Coordenadora do Programa de Fortalecimento aos Empreendimentos Solidários do Movimentam de Organização Comunitária (MOC), uma agricultora filiada à Cooperativa da Agricultura Familiar de Conceição do Coité (COOPAFAM), e a diretora-presidente do Armazém/Arco Sertão.

\section{RESULTADOS E/OU DISCUSSÃO}

O Armazém da Agricultura Familiar, galpão onde funciona a central de comercialização de produtos da agricultura familiar e economia solidária, localizado na BR 116, Serrinha- BA, formaliza-se no ano de 2013, e possui uma diversidades de produtos. No processo de formação, a Arco Sertão Central, organização dos Empreendimentos Econômicos Solidários, que o administra, contou com apoio do Movimento de Organização Comunitária (MOC), Secretaria Estadual de Desenvolvimento Rural (SDR), por meio da Companhia de Desenvolvimento e Ação Regional (CAR), a Secretaria do Trabalho, Emprego, Renda e Esporte (SETRE), a Superintendência de Desenvolvimento Industrial e Comercial (SUDIC), União de Cooperativas da Agricultura Familiar e Economia Solidária (Unicafes) e o Centro Público de Economia Solidária (CESOL), instâncias que foram relevantes para a concretização do projeto. 
Além da comercialização, é declarado pelas participantes que o mesmo atua na promoção da autonomia e condições de empoderamento feminino, por meio de ações desenvolvidas como: palestras, rodas de conversa, curso de formação, entre outras; o que propicia reconhecimento e visibilidade, em especial as mulheres. Oliveira (2004) salienta que as possibilidades de politização acontecem por meio da prática da participação, do desenvolvimento da criticidade e da visibilidade promovidas pelo alcance do trabalho articulado ao coletivo.

Ao versar sobre a parceria entre o Armazém e as mulheres, essas destacam as condições para autonomia que lhes são proporcionadas ao participarem dos empreendimentos produtivos e ressaltam a importância desse instrumento na viabilidade de alternância em suas vidas. Para elas, houve uma mudança de perspectiva a partir do momento que se inseriram no empreendimento, ressaltam uma maior participação social, visto que, antes estavam circunscritas ao espaço privado, o que é possível observar na fala de uma entrevistada.

[...] mulher ela não foi feita para, só para ficar dentro de casa, para ser uma dona de casa. Que mulher quando pode, ela, toda mulher tem, ela pode, ela tem o direito e ela conquista o que ela quiser. Basta pode ter força de vontade para poder conquistar (Diretora-presidente do Armazém, 49 anos, ensino fundamental).

Dessa maneira, a construção do galpão do Armazém da Agricultura Familiar representa relações comerciais pautadas nos princípios do comércio justo. A participação nos espaços de decisão promove mudanças no comportamento das mulheres, como exemplo, mulheres de uma determinada associação, que ao vincular-se ao Armazém, em suas primeiras reuniões não externavam suas opiniões, mas que no decorrer do tempo, ganharam confiança para se posicionar e questionar:

As mulheres não falavam, as mulheres não se comunicavam, as mulheres não, não participava de nada. Era sentada lá só para dizer que foi, como se fosse um jarro. Com a participação nas nossas atividades, com esses cursos de formação de gênero e de tudo, elas se empoderaram, hoje elas assumiram a associação, elas participam de PNAE, participam de ações, participam de várias coisas lá fora (Diretora-presidente do Armazém, 49 anos, ensino fundamental).

Por meio da narrativa da entrevistada percebe-se a importância da participação feminina em espaços público, assim como o poder de fala enquanto expressão da sua legitimidade, por possibilitar as mulheres rurais saírem do lugar de coadjuvante e assumirem o papel de protagonistas nos espaços de poder. Oliveira (2004) destaca que romper com o silenciamento, visibilizar as ações e protagonismo das mulheres são premissas para falar de democracia, participação e autonomia do feminino.

Todavia, a saída do espaço privado, em busca de autonomia e desenvolvimento pessoal não é fácil para as mulheres, elas têm que encarar o exercício da dupla jornada, uma vez que, precisa fazer as atividades domésticas antes de sair de casa e/ou ao retornar. Assim, ao ser inquerida sobre desigualdades que são vivenciadas pelas mulheres e se a inserção dessas tem contribuído para reduzir tal situação, uma entrevistada afirma que sim, mas que para isso as mulheres pagam um alto preço:

Contribui sim, contribui principalmente no processo de formação, né, mas por outro lado às mulheres elas sobrecarregam também, porque elas passam a desenvolver jornadas triplas, porque além dela ser a gestora da cooperativa, 
ela está ali no grupo de produção, ela é mãe, então assim, ela passa a desenvolver várias outras jornadas, né, dentro dessas 24 horas para ela conseguir, né, essa equidade. (Presidente da Unicafes, 35 anos, ensino superior).

Dessa maneira, percebe-se a dificuldade que é para a mulher adentrar os espaços públicos, e também permanecer neles, visto que são muitas demandas que recaem sobre elas, em razão de sua condição de gênero. Isso de certa forma dificulta o alcance de sua autonomia e de uma equidade. A fim de corroborar tal afirmação, Quaresma (2015) explana que, mesmo as mulheres assumindo recursos externos que são relevantes para a agricultura familiar, elas atuam em um regime desigual, com jornadas duplas ou triplas.

A divisão e a manutenção sexual do trabalho se mostram como elemento fundamental da construção histórica de desigualdade sobre as mulheres e que pode ser compreendida como um fator da continuidade das assimetrias vivenciadas pelas mulheres, em especial as rurais.

Quaresma (2015) afirma que mesmo existindo uma crescente introdução das mulheres na esfera pública e mudança no modelo familiar rural, essa mudança é vagarosa e isso pode ser notado nas diferenças entre fatores socioeconômicos de mulheres e homens:

A mulher que se dispõe a ser uma gestora é uma mulher que tem ene jornadas, porque tem que dar conta de todo esse, não é o esquema, de toda essa conjuntura familiar, mas que têm muitas que aos poucos conseguem estar fazendo a divisão sexual do trabalho, aos poucos estão conseguindo reverter esse processo, mas ainda não é uma grande superação, mas principalmente do empoderamento, do que é ser mulher dos seus direitos a gente consegue ver sim essa participação delas e nessa busca dos direitos (Presidente da Unicafes, 35 anos, nível superior).

As diferenças sociais de gênero não se reproduzem como algo recente, esses contrastes são tratados pelos movimentos feministas e de mulheres, e se estabelecem em diversos contextos, entre os quais o meio rural. O não reconhecimento do trabalho da mulher na produção agrícola familiar traduz as discrepâncias de gênero vivenciadas por elas. A negação da condição da mulher enquanto trabalhadora rural é internalizada tanto por elas, como por suas famílias, sendo reproduzido em outros espaços, como sindicatos e associações (MELO 2003).

Diante da inserção em associações e cooperativas, algumas mulheres suscitam a necessidade de uma qualificação profissional a fim de alcançar melhorias em suas vidas. Compreendem, assim, ser esse o caminho para romper com as desigualdades ancoradas na diferenciação de gênero que são socialmente construídas. Nesta perspectiva a presidente da Unicafes revelou que quando concluiu o ensino médio se inseriu em uma cooperativa a fim de obter uma renda, mas que durante o processo sentiu a necessidade de buscar a qualificação educacional, e partiu para realizar um curso superior.

Trajetórias de superação são partes dos contextos que envolvem a condição feminina, muitas das mulheres rurais salientam as conquistas como parte de um percurso que colocam a prova capacidade feminina na ocupação de espaços de deliberação. Assim, Oliveira (2004) explana que a apropriação do conhecimento gera criticidade, amplia horizontes e traz independência. Por meio do acesso à informação que fundamenta seu posicionamento, essas têm o seu poder de argumentação, sustentação e autonomia. 


\section{CONSIDERAÇÕES FINAIS}

Por meio desse trabalho constatou-se que é possível a transformação das condições de vida das mulheres rurais por meio da sua inserção em empreendimentos produtivos, bem como sua vinculação ao Armazém. Nesses espaços coletivos as mulheres conseguem construir estratégias de enfrentamento, criando novas possibilidades, enfrentam preconceitos e vencem desafios por meio de luta e participação.

Almeida, Lüchmann e Ribeiro (2012) discorrem que o associativismo se apresenta como um instrumento básico através do qual uma comunidade pode sair do anonimato e passar a ter maior relevância social, política, ambiental e econômica. A partir de uma associação a comunidade pode se fortalecer e aumentar a probabilidade de atingir os objetivos do grupo.

\section{REFERÊNCIAS}

Almeida, C., Lüchmann, L., \& Ribeiro, E. 2012. Associativismo e representação política feminina no Brasil. Revista Brasileira de Ciência Política, (8), 237-263. CL de (Org.). FRANÇA. (2003). Comércio ético e solidário no Brasil. Fundação Friedrich Ebert. 144 p.

Melo, L. A. D. 2003. Relações de gênero na agricultura familiar: o caso do PRONAF em Afogados da Ingazeira-PE.

Oliveira, A. L. D. 2004. O processo de empoderamento de mulheres trabalhadoras em empreendimentos de economia solidária.

Quaresma, A. P. 2015. Mulheres e quintais agroflorestais: a "ajuda invisível" aos olhos que garante a reprodução da agricultura familiar camponesa amazônica. COLETÂNEA SOBRE ESTUDOS RURAIS E GÊNERO, 35.

REISDORFER, V. K. 2014. Introdução ao cooperativismo. Colégio Politécnico (UFSM). Santa Maria-RS. 